\title{
SINGLE AXIS PV-PANEL TRACKING FOR AUTOMATED STREET LIGHT CONTROLLER
}

\author{
${ }^{1}$ Keerthana.A, ${ }^{2}$ Suresh Kumar.K \\ ${ }^{1}$ UG Scholar, Electronics \& Communication Engineering, KPR Institute of Engineering \\ \& Technology, Coimbatore, Tamilnadu, INDIA. \\ ${ }^{2}$ PG Scholar, La Trobe University, Melbourne, Australia.
}

\begin{abstract}
A Street Light Control framework which works naturally is least demanding as well as the canny framework. This project describes a street lighting application developed utilizing a hybrid powergeneration technology that combines solar energy into a single, unified power generation system. Solar energy vitality is quickly picking up notoriety as an essential method for growing renewable vitality assets. Solar energy following permits more vitality to be delivered in light of the fact that the sun oriented vitality has the capacity stay adjusted to sun. The force from the sun blocked by the earth is roughly $1.8 * 1011 \mathrm{MW}$, which is numerous a huge number of times bigger than the present utilization rate on the earth of all business vitality sources. The design objective of the solar renewable street-light system is to develop a self-sufficient street lighting system that generates and stores electric power whenever solar radiation are available, and then provides lighting during the night time. The bureau for the battery stockpiling and controller circuits ought to be sufficiently little with the goal that it can be promptly installable in many areas.
\end{abstract}

A Light Dependent Resistor is used to activate street light during night time. The RTC is a device which counts data and time. Depending upon time the RTC provides a voltage source which will trigger the motor solar panel to rotate in a direction of light source. There by the solar panel will get activated and provide voltage to the battery to operate depend on load requirement

\section{KEYWORDS}

PIC16F877A, LCD Display, RTC, Solar panel, LDR.

\section{INTRODUCTION}

Instantly we are living in a mechanical world. The vitality assets are getting exhausted and influence our surroundings. So we can try for renewable vitality assets. India is thickly populated and has very sun oriented protection, giving a perfect mix to sun powered power in India. Also India is a tropical nation with more than 300 sunny days; we can richly utilize sun powered vitality equal to almost 5,000 trillion $\mathrm{kWh} /$ year, which is much more than the aggregate vitality utilization of the nation today. So we composed a SOLAR following framework with the assistance of outfitted engine controlled by the prearranged microcontroller. The road light will 
be using the put away vitality from the battery. With a specific end goal to decrease force utilized by the road light two separate burdens are joined (a low utilization and a high utilization knobs are being utilized by necessities).

\section{PROPOSED FRAMEWORK}

This paper depicts a road lighting application created using a cross breed force era innovation that consolidates sun based vitality into a solitary, brought together power era framework. The design objective of the solar hybrid renewable street light system is to develop a self-sufficient street lighting system that generates and stores electric power whenever solar radiation are available, and then provides lighting during the night time. The bureau for the battery stockpiling and controller circuits ought to be sufficiently little so it can be promptly installable in many areas.

Keeping in mind the end goal to acquire the greatest productivity, a microcontroller is utilized to tilt the position of the sun powered board, as indicated by the position of the sun utilizing the outfitted engine. A RTC (Real Time Clock) technique is used to track the solar panel. The RTC is a device which counts time. Depending up on time the RTC provide a Voltage source which will trigger the motor solar panel to rotate in a direction of light source. As time builds the board consequently tracks and resets to unique position after dusk. It again begins to track following 12 hours. A Light Dependent Resister (LDR) is utilized for recognizing evening. Amid dull time, the vitality put away in the battery is devoured by the road light.

Our venture can be further reached out with the assistance of an Infra Red (IR) sensor, by which a high utilization knob is turned ON just in the vicinity of human. Otherwise, a low consumption bulb is normally turned ON, thus saving power to a maximum extent.

The system consists of the following units:

- $\quad$ Controlling unit

- $\quad$ Tracking unit

- $\quad$ Sensing unit

- $\quad$ Lighting unit 


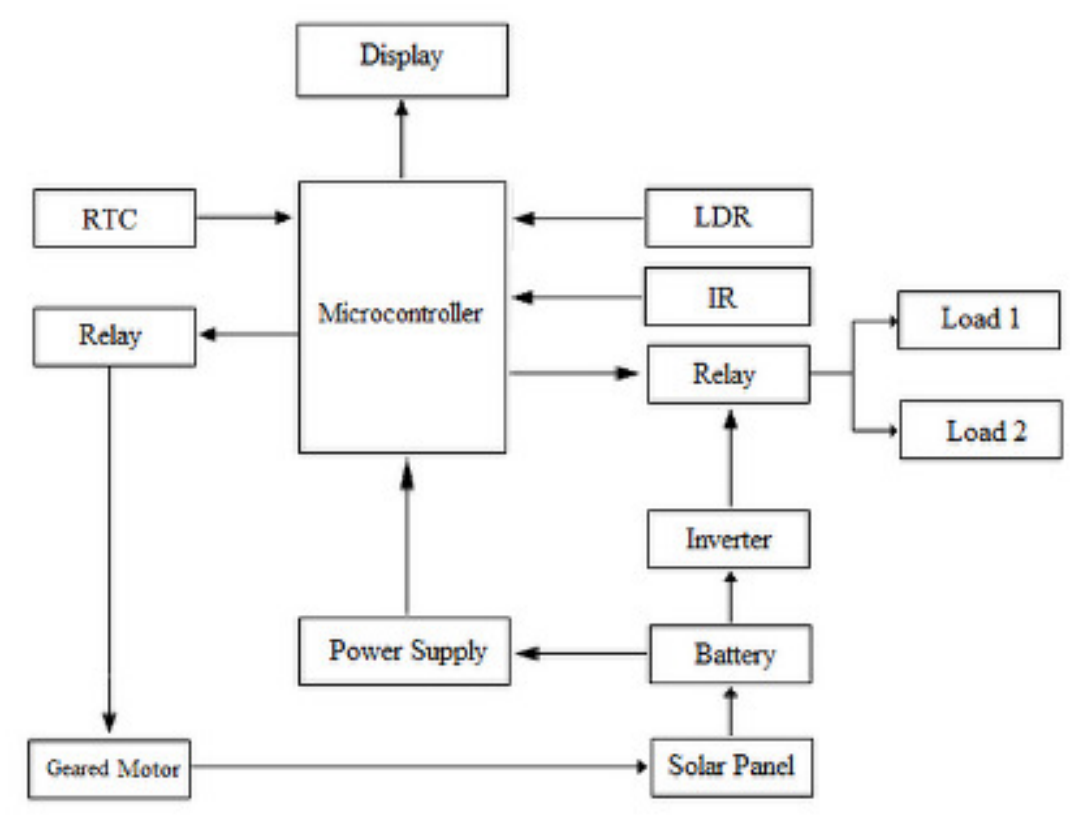

Fig.1 Block diagram of proposed system

\section{CONTROLLING UNIT}

\subsection{INTRODUCTION TO PIC16F877A}

Microcontroller PIC16F877A is one of the PIC Micro Family microcontroller which is noticeable at this moment, start from learner until all specialists. Due to utilizing FLASH memory innovation it can be compose eradicate until thousand times. The prevalence this RISC Microcontroller contrasted over and other microcontroller 8-bit particularly at a velocity of and his code pressure. PIC16F877A have 40 pin by 33 way of I/O.

Ease, low utilization, simple taking care of and adaptability make PIC16F877A relevant even in ranges where microcontrollers had not already been considered (sample: clock capacities, interface substitution in bigger frameworks, coprocessor applications, etc.).In System Programmability of this chip (alongside utilizing just two pins as a part of information exchange) makes conceivable the adaptability of an item, in the wake of amassing and testing have been finished. This ability can be utilized to make sequential construction system generation, to store adjustment information accessible strictly when last testing, or it can be utilized to enhance programs on completed items. 


\subsection{BATTERY}

A battery is a gadget that changes over compound vitality straightforwardly to electrical vitality. It comprises of various voltaic cells; every voltaic cell comprises of two half-cells associated in arrangement by a conductive electrolyte containing anions and cations. One half-cell incorporates electrolyte and the cathode to which anions (contrarily charged particles) relocate, i.e., the anode or negative terminal. The other half-cell incorporates electrolyte and the cathode to which cations (decidedly charged particles) move, i.e., the cathode or positive anode.In the redox reaction that powers the battery, cations are decreased (electrons are incorporated) at the cathode, while anions are oxidized (electrons are removed) at the anode. The cathodes don't touch one another yet are electrically associated by the electrolyte.

\subsection{REAL TIME CLOCK}

\section{GENERAL DESCRIPTION}

The DS1307 serial constant clock (RTC) is a low-power, full parallel coded decimal (BCD) clock/logbook notwithstanding 56 bytes of NV SRAM. Location and information are exchanged serially through an $\mathrm{I} 2 \mathrm{C}^{\mathrm{TM}}$, bidirectional transport. The clock/timetable gives seconds, minutes, hours, day, date, month, and year data. The end of the month date is consequently balanced for quite a long time with less than 31 days, including remedies for jump year. The check works in either the 24-hour or 12-hour group with AM/PM pointer

\subsection{FEATURES}

- $\quad$ Real-Time Clock (RTC) Counts Seconds, Minutes, Hours, Date of the Month, Month, Day of the week, and Year with Leap-Year compensation valid up to 2100

- $\quad$ 56-Byte, Battery-Backed, Nonvolatile (NV) RAM for Data Storage

- $\quad$ I2C Serial Interface

- $\quad$ Programmable Square-Wave Output Signal

- $\quad$ Automatic Power-Fail Detect and Switch Circuitry

- $\quad$ Optional Industrial Temperature Range: $-40^{\circ} \mathrm{C}$ to $+85^{\circ} \mathrm{C}$ 


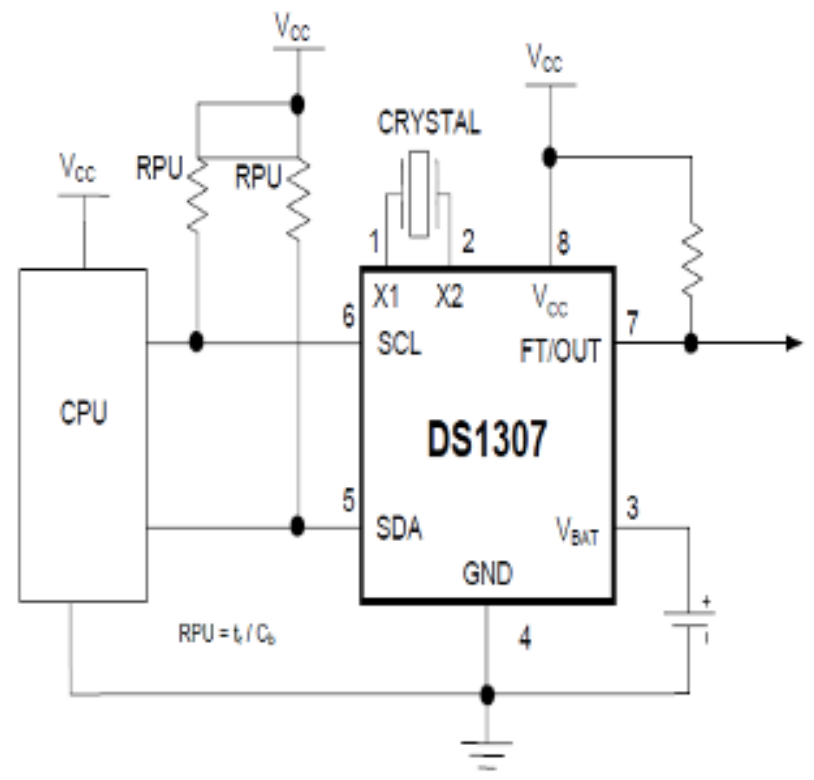

Fig.2 Circuit Diagram of DS1307

\section{TRACKING UNIT}

\subsection{SOLAR PANEL}

The solar panel comprises of cluster of sun oriented cells. A sun oriented cell is any gadget that straightforwardly changes over the vitality in light into electrical vitality through the procedure of photograph voltaic impact. Solar panel boards can produce power with no waste or contamination, or reliance on the Earth's common assets. Solar panel boards have no moving parts so they are extremely dependable and have a long life compass. Solar panels are generally simple to introduce and are low upkeep. Solar panel can be introduced to create power where it is required which uproots the need to transport and disseminate control over long separations to remote zones. In this task polycrystalline silicon board has been utilized on the grounds that it is the most proficient sort and it gives an astounding offset of execution and economy.

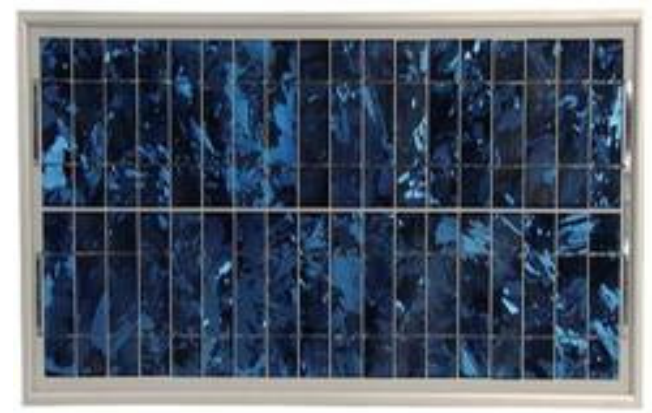

Fig.3 Solar Panel 


\subsection{LCD DISPLAY}

A $16 \times 2$ LCD showcase is utilized for showing the welcome message. LCD presentation is joined with port 1 of the microcontroller. Each pin in port 1 is joined with LCD show. Message is sent through orders by means of serial correspondence. Pin 3.4, 3.5 and 3.6 are associated with control signals. The following are the control signs, they are RS (Register Select), EN (Data Enable) and $\mathrm{R} / \mathrm{W}$ (Read/ Write). Control signs are introduced before sending information.

\subsection{FEATURES}

- 5 x 8 spots with cursor

- Built-in controller (KS 0066 or Equivalent)

$\bullet+5 \mathrm{~V}$ force supply (Also accessible for $+3 \mathrm{~V}$ )

-1/16 obligation cycle

- B/L to be driven by pin 1 , stick 2 or pin 15 , stick 16 or A.K (LED)

- N.V. discretionary for $+3 \mathrm{~V}$ power

\begin{tabular}{|l|c|c|}
\hline \multicolumn{4}{|l|}{ MECHANICAL DATA } \\
\hline ITEM & STANDARD VALUE & UNIT \\
\hline Module Dimension & $80.0 \times 36.0$ & $\mathrm{~mm}$ \\
\hline Viewing Area & $66.0 \times 16.0$ & $\mathrm{~mm}$ \\
\hline Dot Size & $0.56 \times 0.66$ & $\mathrm{~mm}$ \\
\hline Character Size & $2.96 \times 5.56$ & $\mathrm{~mm}$ \\
\hline
\end{tabular}

Table.1 Mechanical data for LCD Display

\subsection{GEARED MOTOR}

"Apparatus Motor" implies a blend of a motor notwithstanding a diminishment gear train. These are regularly helpfully bundled together in one unit. The rigging diminishment (apparatus train) diminishes the pace of the engine, with a comparing increment in torque. Gear degrees range from only a couple of (e.g. 3) to tremendous (e.g. 500). A little degree can be fulfilled with a 
solitary apparatus pair, while a vast proportion obliges a progression of rigging diminishment steps and in this manner more apparatuses. There are many sorts of rigging lessening. Because of a little transmission degree $\mathrm{N}$, the unit may be back drivable, significance you can turn the yield shaft, perhaps by hand, at exact rate $\mathrm{w}$ and reason the motor to rotate at dapper pace NW. A bigger transmission degree $\mathrm{N}$ may make the unit non-back drivable. Each has focal points for diverse circumstances. Back drivability depends on $\mathrm{N}$, as well as on numerous different variables. For extensive N, regularly the greatest yield torque is restricted by the quality of the last riggings, instead of by $\mathrm{N}$ times the engine's torque.

\section{SENSING UNIT}

\subsection{LIGHT DEPENDENT RESISTOR}

LDR, an acronym for light dependent resistor is a resistor whose resistance is reliant on light. It is built utilizing two cadmium sulphide(cds) photoconductive cells with otherworldly reactions like that of the human eye. The cell resistance falls with expanding light power. The resistance of LDR is of the request of Mega Ohms without light and lessens to a couple of ohms in vicinity of light. When the light falls on LDR in this circuit, the resistance of LDR becomes acquainted with low and the entire voltage drop happens over the variable resistance VR1 (10K). Thus the base of transistor (T1) gets high enter and it gets one-sided consequently shining the LED. Exactly when no light falls on LDR, the resistance of LDR becomes acquainted with high so pretty much entire voltage drop happens across over it and the base of transistor is at low potential. So transistor does not gets one-sided nor it gets to be directing, subsequently exchanging off the LED. The affectability of the circuit can be balanced by fluctuating the preset VR1.

\subsection{SENSITIVITY}

The affectability of a photograph finder is the relationship between the light falling on the gadget and the subsequent yield signal.

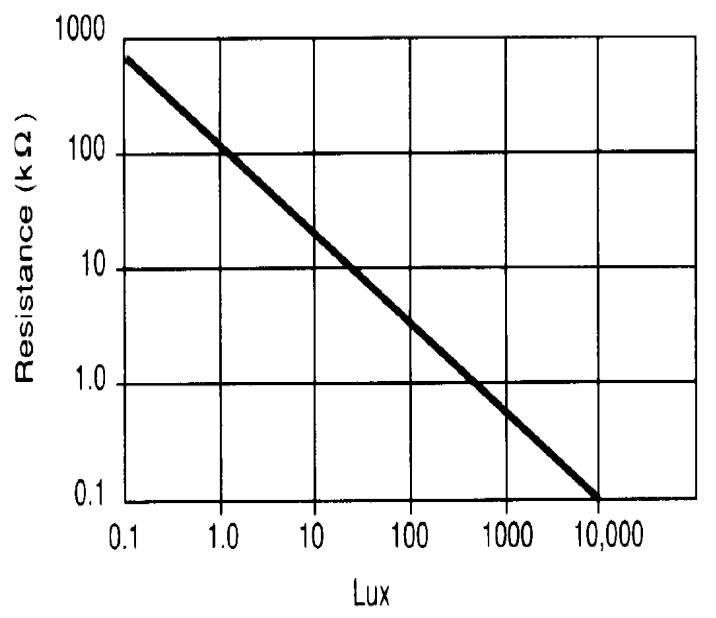

Fig.4 Sensitivity of LDR 


\section{LIGHTING UNIT}

\subsection{POWER SUPPLY}

Since all electronic circuits work just with low D.C. voltage we oblige a power supply unit to give the correct voltage supply. This unit comprises of transformer, rectifier, channel and controller. A.C. voltage routinely $230 \mathrm{~V}$ rms is connected with a transformer which steps that AC voltage down to the level to the pined for AC voltage. A diode rectifier then gives a full-wave corrected voltage that is at first separated by a basic capacitor channel to create a DC voltage. This subsequent DC voltage typically has some swell or AC voltage varieties. controller circuit can utilize this DC info to give DC voltage that has significantly less swell voltage as well as continues as before DC esteem even the DC voltage fluctuates to some degree, or the heap associated with the yield DC voltage changes.

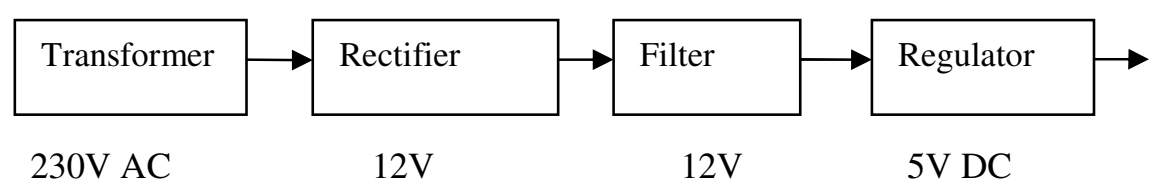

Fig.5 Block diagram for power supply unit

\subsection{FEATURES}

- Universally material in the most changed circuit works in the field of information transfers and little flag innovation

- Versatile outline as it can be conveyed with diverse force utilizations ( $\mathrm{PN}=150$ to 250 $\mathrm{mW}$ ) and in addition with turned around loop extremity

- High dependability because of without slide operation of the center spring

- High-voltage resistance as per FCC

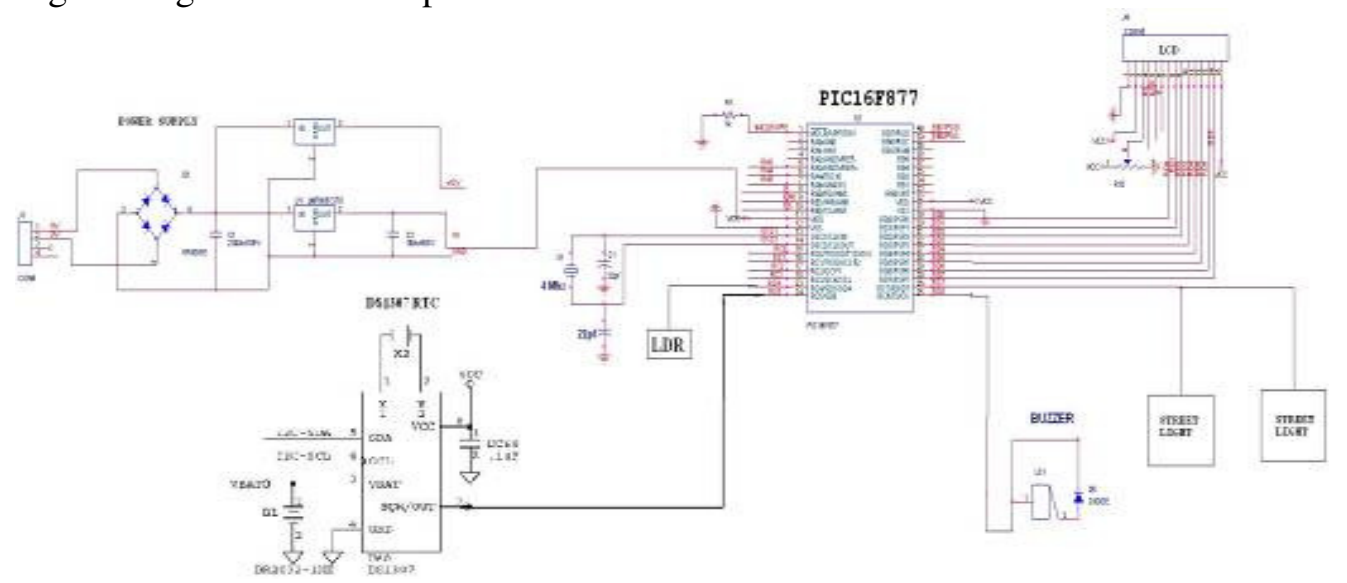


Fig.6 Circuit diagram of proposed system

The overall circuit diagram is shown in Fig.6. The loads are operated by a relay and power is given to one street light at a time.

\section{HARDWARE INVISION OF PROPOSED FRAMEWORK}

Here a microcontroller based solar automatic tracking system always keeps the solar panels aligned with the sun. We are utilizing microcontroller alongside an outfitted engine to tilt the position of the sun oriented board, as indicated by position of the sun. We have used RTC to track the solar panel. As time expands the board consequently tracks and resets to unique position on following day. A LDR is used for identifying night time. Amid dim time, the vitality put away in the battery is devoured by the road light. With the help of Passive Infra-Red(PIR) sensor, high consumption bulb $(5 \mathrm{~W})$ is turned $\mathrm{ON}$ only in the presence of human. Otherwise, a low consumption bulb $(2 \mathrm{~W})$ is normally turned $\mathrm{ON}$, thus saving power to a maximum extent. Thus more than half of the power is usually saved during absence of any motion.

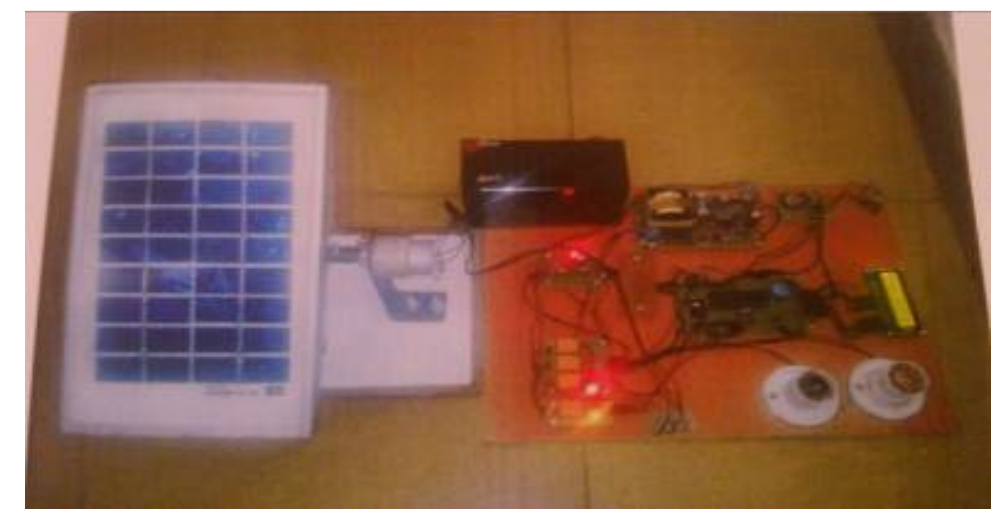

Fig.7 Hardware Invision

\section{CONCLUSION}

By this procedure we can deliver a clean and green force. Consequently electrical force can be produced in country regions itself with ease. This will diminish our reliance on Non- Renewable assets like coal and oil. This has the ability of supplanting all the force plants which are utilizing Non-Renewable assets. A sun based tracker is outlined utilizing the new guideline of utilizing little sun powered cells to capacity as modifying toward oneself light sensors, giving a variable evidence of their relative edge to the sun by distinguishing their voltage yield. By utilizing this technique, the sun oriented tracker was effective in keeping up a sun based show at a sufficiently opposite point to the sun. 


\section{FUTURE ENHANCEMENT}

Real Time Clock is replaced by using Maximum Power Point Tracking (MPPT), which focus the position of panel in the direction of maximum radiation. With the help of a Passive Infra-Red (PIR) sensor, high consumption bulb is turned ON only in the presence of human. Otherwise, a low consumption bulb is normally turned $\mathrm{ON}$, thus saving power to a maximum extent. Further, an Anemometer (Wind stream identifier) is utilization to consistently check the pace of wind, subsequently guaranteeing the setup of the boards.

\section{REFERENCES}

[1] "An Automated Battery Management System for Photovoltaic Systems", by Duryea.S, Syed.I, Lawrence.W, (1999) published in International Journal of Renewable Energy Engineering, Vol 1, No 2.

[2] Fahrenburch, A. and Bube, R. 1983, "Fundamentals of solar cells", Academic Press, New York.

[3] Longlong Zhang, William Gerard Hurley, and Werner Hugo W"olfle,(2011), "A New Approach to Achieve Maximum Power Point Tracking for PV System", IEEE TRANSACTIONS ON POWER ELECTRONICS, VOL. 26, NO. 4, APRIL 2011

[4] Partain, L.D. 1995, "Sollar Cells and their applications", John Wiley \& Sons, New York.

[5] "Solar Tracking System: More Efficient Use of Solar Panels", by Rizk.J, and Chaiko.Y,( 2008), published in WORLD ACADEMY OF SCIENCE, Engineering and Technology.

[6] "Remote Power Supply Using Wind and Solar energy - a Sino-German Technical Cooperation Project", by Weise.E, Klockner.R, Kniel.R, Ma Sheng Hong, Qin Jian Ping,(1995) published in Beijing International Conference on Wind Energy, Beijing.

[7] "Design of a Solar Tracker System for PV Power Plants", by Tiberiu Tudorache1\& Liviu Kreindler,(2010) published in ACTA POLYTECHNICA HUNGARICA, Vol. 7, No. 1.

\section{AUTHORS}

\section{KEERTHANA.A}

She is pursuing final year B.E (Electronics \& Communication Engineering) at KPR Institute of Engineering \& Technology, Coimbatore, Tamilnadu, India. Her field of interest includes Embedded systems \& Medical Electronics. She attended In-plant training at BSNL, All India Radio \& Om Engg Technologies Pvt Ltd (Solar Panel Manufacturing Unit, CBE) which served to gain extensive knowledge about solar panels. She has a great exposure on several researches and exhibited papers in National \& International Conferences.

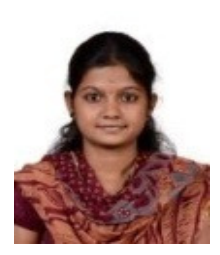

\section{SURESH KUMAR.K}

He is currently pursuing Master of Science at La Trobe University, Melbourne. He obtained his B.E in (Electronics \& Communication Engineering) from KPR Institute of Engineering \& Technology, Coimbatore, Tamilnadu, India. His field of interest includes Embedded systems \& VLSI Design. This exploration was completed under his direction as an aftereffect of his concentrated enthusiasm for this field.

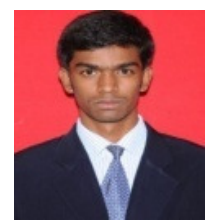

